\title{
NEWS: Capalaba Get Into ATSI Culture
}

Capalaba State High School this year stepped up its support for Aboriginal and Torres Strait Islander students by increasing awareness of their culture.

Capalaba's Aboriginal Student Supportand Parent Awareness program (ASSPA)committee consists of 13 students from Years 8 to 12, their parents and guardians and guidance officer Veda Fitzpatrick.

The committee organised several activities including the purchase of three Aboriginal and Islander works of art on display at the library, and a performance by the Imbala Aboriginal Dance Group, attended by Aboriginal and Islander students and Year 8 and 9 students. The dance group also gave a talk, displayed artefacts and gave students the opportunity to try a didgeridoo.

The Aboriginal and Islander students and some parents and guardians went on an excursion to the NAIDOC Week celebrations in Musgrave Park, South Brisbane, and to North Stradbroke Island where they visited the museum and spoke to a long-time Aboriginal resident.

A collection of Aboriginal artefacts, including individually painted boomerangs, was acquired to start a social science department museum.

The ASSPA Committee also encouraged the involvement of parents and guardians in their children's education. $\square$

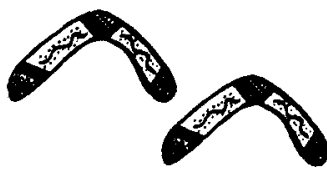

\section{NEWS: Bundy's Artist in Residence}

'Jan has answered questions, and provided insight into artistic concepts and processes,' Ms Quivooy said.

'Her presence has been an inspiration for student artwork, a positive role model for youth and has fostered an opportunity for cultural exchange,' she said.

Ms Henderson is a descendent of the Butchulla people of Fraser Island, and has served as Chairperson of the Korrawinga Aboriginal Corporation for the past three years.

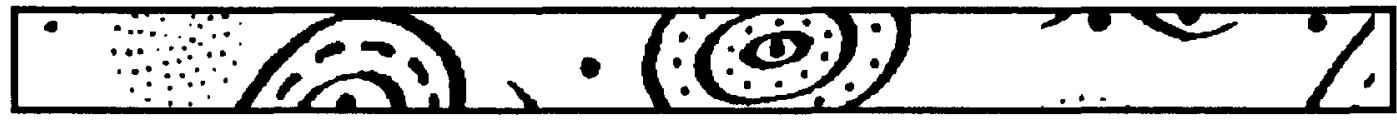

